\title{
Continuous renal replacement therapy improves renal recovery from acute renal failure
}

\author{
[La thérapie continue de remplacement rénal améliore la récupération rénale \\ suivant une insuffisance rénale aiguë]
}

Michael J. Jacka MD MSc FrCP(C), ${ }^{*}$ Xenia Ivancinova BSc, $†$ R. T. Noel Gibney MB FRCP(C)†

Background: Acute renal failure (ARF) occurs in up to $10 \%$ of critically ill patients, with significant associated morbidity and mortality. The optimal mode of renal replacement therapy (RRT) remains controversial. This retrospective study compared continuous renal replacement therapy (CRRT) and intermittent hemodialysis (IHD) for RRT in terms of intensive care unit (ICU) and hospital mortality, and renal recovery.

Methods: We reviewed the records of all patients undergoing RRT for the treatment of ARF over a 12-month period. Patients were compared according to mode of RRT, demographics, physiologic characteristics, and outcomes of ICU and hospital mortality and renal recovery using the Chi square, Student's t test, and multiple logistic regression as appropriate.

Results: I I 6 patients with renal insufficiency underwent RRT during the study period. Of these, 93 had ARF. The severity of illness of CRRT patients was similar to that of IHD patients using APACHE II (25.I vs $23.5, P=0.37$ ), but they required significantly more intensive nursing (therapeutic intervention scale 47.8 vs $37.6, P=$ $0.000 \mathrm{I})$. Mortality was associated with lower $\mathrm{pH}$ at presentation $(P$ $=0.003)$ and increasing age $(P=0.03)$. Renal recovery was significantly more frequent among patients initially treated with CRRT $(2 \mid / 24$ vs $5 / 14, P=0.0003)$. Further investigation to define optimal timing, dose, and duration of RRT may be beneficial.

Conclusions: Although further study is needed, this study suggests that renal recovery may be better after CRRT than IHD for ARF. Mortality was not affected significantly by RRT mode. et de mortalité à l'unité des soins intensifs (USI) et à l'hôpital de même que la récupération rénale.

Méthode : Pour notre étude rétrospective, nous examiné les dossiers de tous les patients traités par TCRR pour l'IRA au cours de 12 mois. Nous avons comparé les patients selon le mode de TCRR, les caractéristiques démographiques et physiologiques, l'évolution à I'USI, la mortalité à l'hôpital et la récupération rénale en utilisant le test du chi deux et le test $t$ de Student et une régression logistique multiple selon le cas.

Résultats : Pendant la période étudiée, 116 patients atteints d'insuffisance rénale, dont 93 avaient une IRA, ont reçu une TCRR. La sévérité de la maladie des patients sous TCRR était comparable à celle des patients sous HDI d'après le score APACHE || $(25$, I vs 23,5, $P=$ $0,37)$, mais nécessitait des soins infirmiers significativement plus intensifs (échelle d'intervention thérapeutique 47,8 vs 37,6, $P=0,0001$ ). La mortalité était plus fréquente avec un $\mathrm{pH}$ plus bas au moment de l'admission $(P=0,003)$ et avec l'âge $(P=0,03)$. La récupération rénale était significativement plus fréquente chez les patients traités initialement avec une TCRR (2//24 vs 5/14,P=0,0003). Une recherche plus poussée visant à définir le moment optimal, la dose et la duré de la TCRR est souhaitable.

Conclusion : La présente recherche indique que la récupération peut être meilleure après une TCRR qu'une HDI pour l'IRA. Le mode de TCRR ne modifie pas significativement la mortalité.
Objectif : L'insuffisance rénale aiguë (IRA) se manifeste chez près de $10 \%$ des grands malades, avec une morbidité et une mortalité accentuées. Le mode optimal de thérapie continue de remplacement rénal (TCRR) reste controversé. Notre étude rétrospective a comparé la TCRR et l'hémodialyse intermittente (HDI) en termes de morbidité

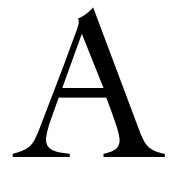

CUTE renal failure (ARF) occurs in up to $10 \%$ of critically ill patients, with significant associated morbidity and mortality. ${ }^{1-7}$ The majority of these patients require at least short-term renal replacement therapy (RRT) and some

From the Department of Anesthesiology* and the Division of Critical Care Medicine, ${ }^{\star} \dagger$ Faculty of Medicine and Dentistry, University of Alberta, Edmonton, Alberta, Canada.

Address correspondence to: Dr. Michael J. Jacka, Department of Anesthesiology and the Division of Critical Care Medicine, Faculty of Medicine and Dentistry, University of Alberta Hospitals, 32B2.32 Walter C. Mackenzie Health Sciences Centre, Edmonton, Alberta

T6G 2B7, Canada. Phone: 780-407-3552; Fax: 780-407-3200; E-mail: mjacka@ualberta.ca

Accepted for publication July 16, 2004.

Revision accepted December 10, 2004. 
will require hemodialysis chronically. $2,3,5$ Although intermittent hemodialysis (IHD) is suitable for renal replacement in patients with chronic stable renal failure, it is often associated with hemodynamic instability, which is especially severe in critically ill patients. This hemodynamic instability commonly precludes satisfactory renal replacement in the critically ill and may have an adverse effect on recovery from ARF. ${ }^{7,8}$

Continuous renal replacement therapy (CRRT) was developed for the treatment of critically ill patients with ARF, is better tolerated hemodynamically than IHD, and is usually applied to patients with multiple organ failure and hemodynamic instability. ${ }^{9-11}$ Three epidemiological studies have analyzed survival in patients with ARF. All concluded that mortality was higher in patients receiving CRRT because of a higher severity of illness, and that CRRT was chosen in those patients primarily because of hemodynamic instability. ${ }^{2,3,12}$ A recent large prospective multicentre study of 839 patients who received RRT for ARF found that patients receiving CRRT had more organ system failures than those receiving IHD and a higher intensive care unit (ICU) mortality, while patients receiving IHD had a higher mortality rate following transfer from the ICU. ${ }^{6}$ A number of studies have attempted to determine whether choice of RRT mode affects outcome. ${ }^{13-21}$ However, even meta-analyses of these studies have provided conflicting results. ${ }^{22,23}$ Major confounding factors have been inability of some patients randomized to the IHD arms to tolerate therapy due to hemodynamic instability or the exclusion of patients with baseline hemodynamic instability from some studies. ${ }^{17,20}$

This study investigated the effectiveness of CRRT and IHD in a mixed medical-surgical population, in terms of survival and renal recovery.

\section{Methods}

The E.G. King Intensive Care Unit at the University of Alberta Hospitals provides tertiary critical care services in a referral hospital with an active liver transplant service, receiving approximately 1,400 admissions per year, with RRT being required in 6 to $8 \%$. RRT was provided by specially-trained critical care nurses using Gambro Prisma CRRT machines (Gambro Canada, St. Leonard, QC, Canada) and Gambro Integra hemodialysis machines (Gambro Canada, St. Leonard, QC, Canada). RRT was prescribed by the attending intensivist, who also prescribed mode and dose. Availability of equipment was seldom a factor in the selection of mode or dose of RRT. The mode of CRRT in all patients was continuous venovenous hemodiafiltration using 1 to $1.5 \mathrm{~L}$ of both dialysate and replacement fluid. The Fresenius F7 dialyzer (Fresenius Medical Care North America, San Diego, CA, USA) was used for IHD. Treatment duration varied between four and six hours, as clinically indicated, for IHD.

Institutional Health Ethics Review Board approval was obtained. Informed consent was waived for this study. The records of all patients with ARF undergoing RRT between January 1, 2000 and December 31, 2000 were reviewed. Patients with chronic renal failure receiving chronic hemodialysis and patients treated with hemodialysis for drug overdose and toxic ingestion were excluded. APACHE II and therapeutic intervention scale scores (TISS) were calculated on all patients. ${ }^{24,25}$

The outcomes of mortality and recovery of renal function at the time of hospital discharge were compared according to mode of RRT. Univariable analysis of factors potentially associated with these outcomes was done, followed by reverse stepwise multivariable logistic regression analysis of all univariable factors considered. All analyses were performed using SAS version 8 (® SAS Institute, Cary, NC, USA).

\section{Results}

One hundred and sixteen (116) patients received RRT during the study period, with 66 receiving CRRT and 50 receiving IHD. Of these, 16 had chronic renal failure and were excluded. Seven patients received IHD for treatment of drug overdose and were also excluded, leaving 93 patients on whom the remainder of the analysis is based.

The mean age ( 54.7 vs 62.6, Table I, $P=0.02$ ) was lower in the CRRT group. The sex distribution was similar as was the distribution of diagnostic groups. The APACHE II score was similar between groups (25.1 vs 23.5, $P=0.37$ ). Although the serum creatinine level on admission to ICU was lower in the CRRT group (289 vs $410 \mu \mathrm{mol} \cdot \mathrm{L}^{-1}, P=0.02$ ), the RRT groups were equivalent at institution of RRT (Table II). The use of vasoactive drugs was higher among CRRT patients $(40: 25$ vs 10:18, $P=0.02)$. All patients in both groups were intubated and mechanically ventilated.

The indications for RRT were very similar between groups (Table II), including the frequency of oliguria $(P=0.27)$ and elevated serum creatinine (creatinine greater than $\left.600 \mu \mathrm{mol} \cdot \mathrm{L}^{-1}, P=0.48\right)$. More patients receiving CRRT had concomitant acute pulmonary conditions (32 vs $6, P=0.003$, Table III). All 32 patients with liver failure received CRRT (Table III). TISS of CRRT patients were significantly higher than those of IHD patients ( $47.8 v s 37.6, P=0.0001)$. No 
TABLE I Demographics*

\begin{tabular}{|c|c|c|c|}
\hline & CRRT $(n=65)$ & $I H D(n=28)$ & P value \\
\hline Time to RRT (hr) & $84( \pm 80)$ & $68( \pm 60)$ & 0.52 \\
\hline Age (yr) & $54.7( \pm 15.4)$ & $62.6( \pm 13.4)$ & 0.02 \\
\hline \multicolumn{4}{|l|}{ Gender } \\
\hline Male & $45(69 \%)$ & $17(61 \%)$ & \multirow[t]{2}{*}{0.43} \\
\hline Female & $20(31 \%)$ & $11(39 \%)$ & \\
\hline \multicolumn{4}{|l|}{ Diagnostic group } \\
\hline Medical & $46(71 \%)$ & $17(61 \%)$ & \multirow{3}{*}{0.23} \\
\hline Surgical & $12(18 \%)$ & $10(36 \%)$ & \\
\hline Transplant & $7(11 \%)$ & $1(3 \%)$ & \\
\hline APACHE II score & $25.1( \pm 7.3)$ & $23.5( \pm 8.5)$ & 0.37 \\
\hline TISS & $47.8( \pm 1.3)$ & $37.6( \pm 2.0)$ & 0.0001 \\
\hline Mechanical ventilation & $65(100 \%)$ & $28(100 \%)$ & 1.0 \\
\hline Acute lung injury & $32(49 \%)$ & $6(21 \%)$ & 0.01 \\
\hline $\begin{array}{l}\text { Admission serum } \\
\text { creatinine }\left(\mu \mathrm{moL} \cdot \mathrm{L}^{-1}\right)\end{array}$ & $289( \pm 217)$ & $410( \pm 223)$ & 0.02 \\
\hline Vasoactive drugs require & $40(62 \%)$ & $10(36 \%)$ & 0.02 \\
\hline
\end{tabular}

*Values are means \pm standard error where applicable. CRRT $=$ continuous renal replacement therapy; IHD = intermittent hemodialysis; RRT = renal replacement therapy; TISS = therapeutic intervention scale.

TABLE II Indications for RRT

\begin{tabular}{llll}
\hline & $\begin{array}{l}\text { CRRT } \\
(n=65) *\end{array}$ & $\begin{array}{l}\text { IHD } \\
(n=28) *\end{array}$ & P value \\
\hline Oliguria $<0.5 \mathrm{~mL} \cdot \mathrm{kg}^{-1} \cdot \mathrm{hr}^{-1}$ & $47(73 \%)$ & $17(60 \%)$ & 0.27 \\
Creatinine $>600 \mu \mathrm{moL} \cdot \mathrm{L}^{-1}$ & $8(12 \%)$ & $5(18 \%)$ & 0.48 \\
$\mathrm{Urea}>35 \mathrm{mmoL} \cdot \mathrm{L}^{-1}$ & $11(17 \%)$ & $10(36 \%)$ & 0.05 \\
$\mathrm{~K}>6 \mathrm{mmoL} \cdot \mathrm{L}^{-1}$ & $3(5 \%)$ & $2(7 \%)$ & 0.62 \\
$\mathrm{pH}<7.2$ & $14(22 \%)$ & $6(21 \%)$ & 0.99 \\
\hline
\end{tabular}

*Patients were counted more than once if multiple indications for RRT were present. CRRT = continuous renal replacement therapy; $\mathrm{IHD}=$ intermittent hemodialysis; RRT = renal replacement therapy.

patients treated with IHD were subsequently changed to CRRT. Eighteen patients initially commenced on CRRT were later changed to IHD once their condition had improved and they no longer required vasoactive medications. Use of norepinephrine and epinephrine was significantly more common among patients with CRRT (Table III).

In the univariable analysis (not shown), mode of RRT, presence of an acute pulmonary condition, hepatic failure and low $\mathrm{pH}$ were closely associated with ICU and hospital mortality, but also with renal recovery. After multivariable analysis (Table IV), ICU mortality remained closely associated with low $\mathrm{pH}$ at presentation [odds ratio (OR) 18, $P=0.001$ ]. Hospital mortality was also associated with low $\mathrm{pH}$ at presentation (OR 8, $P=0.003)$. Renal recovery was associated with the initial use of CRRT instead of
TABLE III Comparison of indications for RRT mode at initiation of RRT

\begin{tabular}{llll}
\hline & $\begin{array}{l}\text { CRRT } \\
(n=65)\end{array}$ & $\begin{array}{l}\text { IHD } \\
(n=28)\end{array}$ & P value \\
\hline Cerebral injury & $1(2 \%)$ & $0(0 \%)$ & 0.51 \\
Hepatic failure & $31(47 \%)$ & $0(0 \%)$ & 0.0001 \\
Dopamine $>5 \mu \mathrm{gg} \cdot \mathrm{kg}^{-1} \cdot \mathrm{min}^{-1}$ & $18(27 \%)$ & $6(18 \%)$ & 0.53 \\
Epinephrine & $15(23 \%)$ & $1(3 \%)$ & 0.02 \\
Norepinephrine & $29(44 \%)$ & $5(15 \%)$ & 0.014 \\
$\begin{array}{l}\text { Cross over to alternate } \\
\text { mode of RRT }\end{array}$ & $18(67 \%)$ & $0(0 \%)$ & 0.002 \\
\hline
\end{tabular}

CRRT $=$ continuous renal replacement therapy; IHD $=$ intermit tent hemodialysis; RRT = renal replacement therapy.

IHD (OR 0.04, $P=0.006$ ), and with lower age (OR $0.89, P=0.03)$. Although ICU mortality was higher in the CRRT group $(P=0.02$, Table Va), hospital mortality was not significantly different between groups $(P=0.24$, Table $\mathrm{Vb})$. Renal recovery (dialysis no longer required) was significantly more common among patients initially treated with CRRT $(P=$ 0.0003 , Table Vc).

\section{Discussion}

The major finding of our study is that recovery of renal function (and freedom from dialysis) was significantly higher among survivors initially treated with CRRT (88\%) than IHD (36\%). The higher frequency of renal recovery was present despite a higher severity of illness, more frequent use of vasoactive drugs, lower $\mathrm{pH}$, and higher frequency of liver failure, all of which should have worsened end-organ perfusion and renal function. Two North American studies found that a third of ARF survivors required chronic dialysis, while a large survey of ICUs in Australia, found that only $15.7 \%$ of ARF survivors were dialysis-dependent and that most of those had premorbid renal impairment. ${ }^{2,5,12}$ A majority of the patients in the North American studies received IHD while virtually all of the patients in the Australian study were treated with CRRT. In Mehta's study, there was a trend towards more complete renal recovery in the CRRT group, despite a higher severity of illness. ${ }^{20}$ Shorter times to renal recovery have also been reported for CRRT compared to IHD. ${ }^{11}$

Within our study's design limitations, these findings contribute to the debate about the mortality and organsalvage benefits of CRRT. The inconsistent finding of a mortality effect in the literature may have more to do with other systemic effects of the underlying process leading to ICU admission than with mode of RRT. 19,26 
TABLE IV Multivariable logistic analysis of outcomes

\begin{tabular}{|c|c|c|c|c|c|c|}
\hline & \multicolumn{2}{|c|}{ ICU mortality } & \multicolumn{2}{|c|}{ Hospital mortality } & \multicolumn{2}{|c|}{ Renal recovery } \\
\hline & Odds ratio * & $P$ & Odds ratio & $P$ & Odds ratio & $P$ \\
\hline $\mathrm{pH}$ & $18(8,30)$ & 0.001 & $8(5,10)$ & 0.003 & & \\
\hline Age & & & $0.96(0.93,0.99)$ & 0.02 & $0.89(0.80,0.99)$ & 0.03 \\
\hline RRT mode & & & & & $0.04(0.004,0.41)$ & 0.006 \\
\hline
\end{tabular}

*Odds ratio $( \pm 95 \%$ confidence limits $)$. ICU $=$ intensive care unit; RRT = renal replacement therapy.

TABLE V

\begin{tabular}{|c|c|c|c|}
\hline \multicolumn{4}{|c|}{ A) ICU survival $v s$ RRT mode } \\
\hline & Survived & Died & \\
\hline CRRT & $29(45 \%)$ & $36(55 \%)$ & \\
\hline IHD & $20(71 \%)$ & $8(29 \%)$ & $P=0.02$ \\
\hline \multicolumn{4}{|c|}{ B) Hospital survival ps RRT mode } \\
\hline & Survived & Died & \\
\hline CRRT & $24(37 \%)$ & $41(63 \%)$ & \\
\hline IHD & $14(50 \%)$ & $14(50 \%)$ & $P=0.24$ \\
\hline \multicolumn{4}{|c|}{ C) Renal recovery $v s$ RRT mode } \\
\hline & Recovered & Chronic dialysis & \\
\hline CRRT & $21(87 \%)$ & $3(13 \%)$ & \\
\hline IHD & $5(36 \%)$ & $9(63 \%)$ & $P=0.0003$ \\
\hline
\end{tabular}

RRT $=$ renal replacement therapy; CRRT $=$ continuous renal replacement therapy; IHD $=$ intermittent hemodialysis.

Multiple effects of CRRT can be implicated in the higher observed renal recovery, including improved hemodynamic stability (and more constant perfusion of the kidney, avoiding the peaks and troughs associated with IHD), and removal of cytokines. ${ }^{7,8,10,11,26}$ Nonetheless, prospective randomized evaluation will remain the most capable tool to define the effect of RRT mode on renal recovery and survival.

The ICU mortality was $47 \%$ among all study patients receiving RRT, significantly higher among patients receiving CRRT (55\%) than those initially receiving $\operatorname{IHD}(29 \%, P=0.02)$. The direction of this difference was expected since CRRT was originally intended for a sicker population requiring more intensive management, which was confirmed by the higher TISS, and greater requirement for vasopressors in the CRRT group. The hospital mortality was not significantly different between groups $(63 \%$ vs $50 \%, P=$ $0.24)$. This pattern of higher post-ICU mortality in the IHD group was also observed by Metnitz et al. and may suggest the presence of unresolved inflammatory processes or co-morbid conditions. ${ }^{6}$ Improved outcomes have been reported with an earlier initiation of RRT, however, there was no difference in time to RRT in our study. ${ }^{27,28}$ Overall, the hospital mortality in this study was slightly lower than predicted from APACHE II scores (observed 59\% vs predicted 61\%). This centre supports an active liver transplant service, with a large proportion of Child's C classification patients included in the CRRT group. APACHE II does not place significant weight on liver failure, and the predicted mortality of these patients may have been higher with a more-inclusive scoring system. ${ }^{24}$

Paganini et al. found a male gender, non-surgical diagnostic group, and thrombocytopenia to be associated with mortality, but we found none of these to be significant. ${ }^{29}$ They also found hyperbilirubinemia to be associated with mortality, which concurs with our results. These conflicting findings support the need for further modifications to critical care scoring systems, to incorporate the importance of renal insufficiency, hepatic insufficiency, and the use and type of vasoactive support.

The major factor correlating with mortality in this study was metabolic acidosis on admission to the ICU. In this respect, Uchino et al. found that CRRT was more effective than IHD in correcting acidosis and other electrolyte imbalances. ${ }^{30}$

Manns et al. have shown, not surprisingly, that CRRT is more expensive to perform than IHD. ${ }^{31}$ However, they also demonstrated a trend towards better renal recovery in the CRRT group despite significantly lower mean arterial pressure and a trend towards higher APACHE II scores. Our study, albeit retrospective, is the first to find significantly improved renal recovery following initial therapy with CRRT compared to IHD. The study also outlines that choosing a mode of RRT for critically ill patients is a dynamic process with a need to modify modes of therapy as the patient's condition stabilizes. Recovery of renal function can result in significant improvement in the quality of life of survivors from critical illness in addition to significant savings from the avoidance of chronic dialysis in already overburdened chronic dialysis units. ${ }^{32,33}$

In conclusion, the major finding of our study is that renal recovery was substantially higher when CRRT was used for the initial management of ARF in a cohort of critically ill patients. 


\section{References}

1 Levy EM, Viscoli CM, Horwitz RI. The effect of acute renal failure on mortality. A cohort analysis. JAMA 1996; 275: 1489-94.

2 Chertow GM, Christiansen CL, Cleary PD, Munro C, Lazarus JM. Prognostic stratification in critically ill patients with acute renal failure requiring dialysis. Arch Intern Med 1995; 155: 1505-11.

3 Liano F, Pascual J. Epidemiology of acute renal failure: a prospective, multicenter, community-based study. Madrid Acute Renal Failure Study Group. Kidney Int 1996; 50: 811-8.

4 Brivet FG, Kleinknecht DJ, Loirat P, Landais PJ. Acute renal failure in intensive care units - causes, outcome, and prognostic factors of hospital mortality: a prospective, multicenter study. French Study Group on Acute Renal Failure. Crit Care Med 1996; 24: 192-8.

5 Silvester W, Bellomo R, Cole L. Epidemiology, management, and outcome of severe acute renal failure of critical illness in Australia. Crit Care Med 2001; 29: 1910-5.

6 Metnitz PG, Krenn CG, Steltzer H, et al. Effect of acute renal failure requiring renal replacement therapy on outcome in critically ill patients. Crit Care Med 2002; 30: 2051-8.

7 Kelleher SP, Robinette JB, Miller F, Conger JD. Effect of hemorrhagic reduction in blood pressure on recovery from acute renal failure. Kidney Int 1987; 31: 725-30.

8 Conger JD, Robinette JB, Hammond WS. Differences in vascular reactivity in models of ischemic acute renal failure. Kidney Int 1991; 39: 1087-97.

9 Kramer P, Kaufhold G, Grone HJ, et al. Management of anuric intensive-care patients with arteriovenous hemofiltration. Int J Artif Organs 1980; 3: 225-30.

10 Davenport A, Will EJ, Davidson AM. Improved cardiovascular stability during continuous modes of renal replacement therapy in critically ill patients with acute hepatic and renal failure. Crit Care Med 1993; 21: 328-38.

11 van Bommel EF, Bouvy ND, So KL, et al. Acute dialytic support for the critically ill: intermittent hemodialysis versus continuous arteriovenous hemodiafiltration. Am J Nephrol 1995; 15: 192-200.

12 Cosentino F, Chaff C, Piedmonte M. Risk factors influencing survival in ICU acute renal failure. Nephrol Dial Transplant 1994; 9(Suppl IV): 179-82.

13 Bellomo R, Parkin G, Love J, Boyce N. A prospective comparative study of continuous arteriovenous hemodiafiltration and continuous venovenous hemodiafiltration in critically ill patients. Am J Kidney Dis 1993; $21: 400-4$.

14 Bellomo R, Mansfield D, Rumble S, Shapiro J, Parkin G, Boyce N. A comparison of conventional dialytic therapy and acute continuous hemodiafiltration in the management of acute renal failure in the critically ill. Ren Fail 1993; 15: 595-602.

15 Bellomo R, Farmer M, Boyce N. A prospective study of continuous hemodiafiltration in the management of severe acute renal failure in critically ill surgical patients. Ren Fail 1994; 16: 759-66.

16 Kruczynski K, Irvine-Bird K, Toffelmire EB, Morton $A R$. A comparison of continuous arteriovenous hemofiltration and intermittent hemodialysis in acute renal failure patients in the intensive care unit. ASAIO J 1993; 39: M778-81.

17 Kierdorf HP, Sieberth HG. Continuous renal replacement therapies versus intermittent hemodialysis in acute renal failure: what do we know? Am J Kidney Dis 1996; 28(Suppl 3): 590-6.

18 Misset B, Timsit JF, Chevret S, Renaud B, Tamion F, Carlet J. A randomized cross-over comparison of the hemodynamic response to intermittent hemodialysis and continuous hemofiltration in ICU patients with acute renal failure. Intensive Care Med 1996; 22: 742-6.

19 Swartz RD, Messana JM, Orzol S, Port FK. Comparing continuous hemofiltration with hemodialysis in patients with severe acute renal failure. Am J Kidney Dis 1999; 34: 424-32.

20 Mebta RL, McDonald B, Gabbai FB, et al. A randomized clinical trial of continuous versus intermittent dialysis for acute renal failure. Kidney Int 2001; 60: 1154-63.

21 Guerin C, Girard R, Selli JM, Ayzac L. Intermittent versus continuous renal replacement therapy for acute renal failure in intensive care units: results from a multicenter prospective epidemiological survey. Intensive Care Med 2002; 28: 1411-8.

22 Kellum JA, Angus DC, Johnson JP, et al. Continuous versus intermittent renal replacement therapy: a metaanalysis. Intensive Care Med 2002; 28: 29-37.

23 Tonelli M, Manns B, Feller-Kopman D. Acute renal failure in the intensive care unit: a systematic review of the impact of dialytic modality on mortality and renal recovery. Am J Kidney Dis 2002; 40: 875-85.

24 Knaus WA, Draper EA, Wagner DP, Zimmerman JE. APACHE II: a severity of disease classification system. Crit Care Med 1985; 13: 818-29.

25 Keene AR, Cullen DJ. Therapeutic intervention scoring system: update 1983. Crit Care Med 1983; 11: 1-3.

26 Simmons EM, Himmelfarb J, Sezer MT, et al. Plasma cytokine levels predict mortality in patients with acute renal failure. Kidney Int 2004; 65: 1357-65.

27 Kresse S, Schlee H, Deuber HJ, Koall W, Osten B. Influence of renal replacement therapy on outcome of patients with acute renal failure. Kidney Int 1999; 
56(Suppl 72): S75-8.

28 Gettings LG, Reynolds HN, Scalea T. Outcome in posttraumatic acute renal failure when continuous renal replacement therapy is applied early vs. late. Intensive Care Med 1999; 25: 805-13.

29 Paganini EP, Tapolyai $M$, Goormastic $M$, et al. Establishing a dialysis therapy/patient outcome link in intensive care unit acute dialysis for patients with acute renal failure. Am J Kidney Dis 1996; 28(Suppl 3):

S81-9.

30 Uchino S, Bellomo R, Ronco C. Intermittent versus continuous renal replacement therapy in the ICU: impact on electrolyte and acid-base balance. Intensive Care Med 2001; 27: 1037-43.

31 Manns B, Doig CJ, Lee H, et al. Cost of acute renal failure requiring dialysis in the intensive care unit: clinical and resource implications of renal recovery. Crit Care Med 2003; 31: 449-55.

32 Merkus MP, Jager KJ, Dekker FW, Boeschoten EW, Stevens P, Krediet RT. Quality of life in patients on chronic dialysis: self-assessment 3 months after the start of treatment. The Necosad Study Group. Am J Kidney Dis 1997; 29: 584-92.

33 de Wit GA, Ramsteijn PG, de Charro FT. Economic evaluation of end stage renal disease treatment. Health Policy 1998; 44: 215-32. 